\title{
New Anticoagulants for Atrial Fibrillation: The Beginning of a A New Era in Stroke Prevention
}

\author{
David J. Gladstone, Karen M. Earl, Tammy J. Bungard, Jafna L. Cox, Alan Bell, Paul Dorian, \\ Naeem Dean, Thao Huynh, Anil Chopra, John Eikelboom, Ashfaq Shuaib
}

Can. J. Neurol. Sci. 2011; 38: 777-782

Every day in Canada, patients are hospitalized with disabling and fatal strokes related to untreated - or sub-optimally treated - atrial fibrillation (AF). To avert a looming public health crisis of AF-related strokes, clinicians and policy-makers must take action to close the practice gaps and ensure Canadians with AF have access to optimal evidence-based therapies. To date, the provision of appropriate anticoagulant therapy to prevent ischemic stroke in individuals with $\mathrm{AF}$ has proven challenging due to the limitations of warfarin and system-related obstacles to its effective delivery. Now, as the first of a new generation of oral anticoagulants has launched, the field of AF is undergoing a renaissance and there is renewed optimism about the future of AF care. Approval of dabigatran etexilate for AF patients by Health Canada and the FDA in October 2010, together with the trial results of rivaroxaban and apixaban in AF announced in 2010, marks the beginning of a new era in AF management. This paper presents the views of an interdisciplinary group of healthcare professionals interested in stroke prevention to help put these developments into context. Part 1 reviews the "state of the gap" in the warfarin era. Part 2 presents the "state of the art" in new anticoagulant therapies and the potential impact for improving stroke prevention in Canada. Part 3 highlights limitations and uncertainties that need to be addressed in this new era of anticoagulation.

\section{The Burden of Atrial Fibrillation (AF)-Related Strokes}

Stroke is the second leading cause of death globally for individuals over age 60 years and a major cause of long-term physical and cognitive disability. In Canada, approximately 50,000 strokes occur annually costing $\$ 3.6$ billion. $^{1}$ Atrial fibrillation accounts for about one in six strokes (one in four in the elderly), and AF-related strokes are more severe on average than strokes in individuals without AF. As such, AF is a common and potentially preventable cause of stroke-related deaths, disability and dementia. In the Registry of the Canadian Stroke Network, AF was present in one-quarter of $>12,000$ consecutive patients presenting to hospital within an ischemic stroke event between 2003-2007. ${ }^{2}$ The prevalence of AF in Canada is about 250,000 , and with an aging population the burden of AF-related strokes is expected to increase further. The number of Canadians aged $\geq 65$ years is predicted to rise from 4.8 to 10.4 million over the next 25 years, 3,4 and the number of individuals with AF is projected to increase 2.5 fold by $2050 .^{5}$ Thus, there is a pressing public health need to improve the appropriate use of existing therapy (warfarin) and to develop new therapies for primary and secondary stroke prevention.

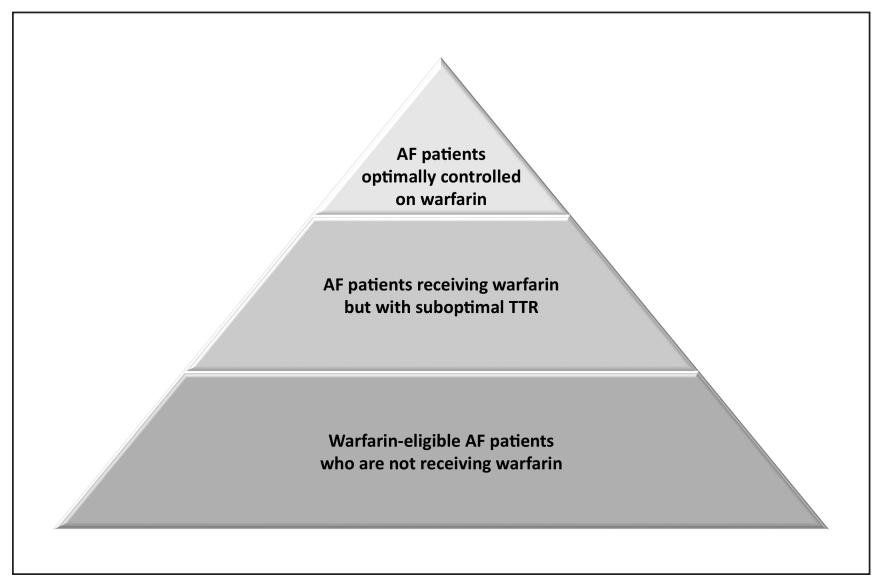

Figure: Schematic of the Practice Gap in Anticoagulation for Atrial Fibrillation. AF patients treated with warfarin who maintain a high time in therapeutic range (TTR) represent the "tip of the iceberg", whereas many more patients with $A F$ are not being maximally treated for stroke prevention.

\section{Part 1. Current Anticoagulant Therapy for AF: The State of the Gap}

The underuse of warfarin for eligible high-risk patients with $\mathrm{AF}$ represents one of the greatest unsolved practice gaps in stroke prevention. Warfarin is a highly efficacious anticoagulant but despite its proven benefits in stroke risk reduction $(64 \%$ RRR vs. placebo; $37 \%$ vs. antiplatelet therapy), ${ }^{6}$ it remains greatly underutilized. The care gaps are staggering - simply put,

\footnotetext{
From the Regional Stroke Centre and Division of Neurology, Department of Medicine and Brain Sciences Program, Sunnybrook Health Sciences Centre, and Division of Neurology, Department of Medicine, University of Toronto, (DJG); Department of Family Medicine, University of Toronto, (AB); Division of Cardiology, St Michael's Hospital and Department of Medicine, University of Toronto, (PD); Emergency Medicine, University Health Network, and Department of Medicine, University of Toronto, Toronto (AC); Department of Medicine, McMaster University, Hamilton (JE); Anticoagulation Management Service, Division of Cardiology, University of Alberta, Edmonton (TJB); EBM Consulting, Inc., Oakville, Ontario (KME); Division of Cardiology, Departments of Medicine and Community Health and Epidemiology, Dalhousie University, Halifax, Nova Scotia (JLC); Division of Cardiology, McGill Health University Center, Montreal (TH); Stroke Program, Royal Alexandra Hospital (ND); Division of Neurology, University of Alberta Hospital, Edmonton, Alberta (AS). Received February 1, 2011. Final Revisions Submitted April 12, 2011. Correspondence to: David J. Gladstone, Regional Stroke Prevention Clinic, Sunnybrook Health Sciences Centre, 2075 Bayview Avenue, Room A442, Toronto, Ontario, M4N 3M5, Canada.
} 
only about half of eligible patients actually receive warfarin, ${ }^{7}$ and those who are taking it are outside the therapeutic international normalized ratio (INR) range about half the time..$^{8,9}$ (Figure) In the Registry of the Canadian Stroke Network's study of 597 consecutive hospitalized ischemic stroke patients with pre-existing AF who were known to be at high risk for emboli and had no contraindications to anticoagulation, only $39 \%$ of this "ideal" cohort had been receiving warfarin pre-stroke and the majority was subtherapeutic; overall, only one in ten was therapeutically anticoagulated (INR $\geq 2.0$ ) at the time of stroke. ${ }^{10}$ Thus, many more strokes could likely be avoided (or lessened in severity ${ }^{11}$ ) if anticoagulant therapy were optimized.

The net benefit of warfarin in stroke prevention is dependent on maintaining the INR in a narrow therapeutic range, i.e. 2.03.0 for non-valvular AF. ${ }^{12}$ Time in therapeutic range (TTR) is generally highest in well-controlled environments such as clinical trials and dedicated anticoagulant management programs, yet still only reaches approximately $65 \% .{ }^{8}$ The balance between benefit and risk favours warfarin over dual antiplatelet therapy (Acetylsalicyclic acid (ASA) plus clopidogrel) only when the TTR is at least $60 \% .{ }^{12}$ The vast majority of Canadians with AF are managed in primary care; unlike some countries, access to dedicated anticoagulant management programs in Canada is very limited..$^{8,13}$ In a Canadian study of warfarin treated AF patients presenting to hospital, INR was therapeutic in only $37 \% .{ }^{14}$ A recent Canadian study found warfarin was prescribed at emergency department (ED) discharge for only $45 \%$ of patients presenting with AF and CHADS2 score $\geq 2 .{ }^{15}$ Warfarin discontinuation rates are also high: for patients prescribed warfarin, adherence in large studies is only $45 \%$ at two years and one-third at five years. ${ }^{16,17}$
The dictum "primum non nocere" may conflict with warfarin prescribing when doubt exists over how well the target anticoagulant level can be maintained. Intracranial hemorrhage is a feared outcome associated with anticoagulant therapy and is more common in patients with poor INR control. ${ }^{12}$ Warfarin is the fourth most common medication implicated in ED visits for adverse drug events. ${ }^{18}$ Fear of bleeding side effects is entrenched in practice; clinicians tend to overestimate warfarin's bleeding risks and underestimate its benefits,${ }^{19}$ an attitude that results in under-dosing or a decision not to initiate therapy for eligible patients who would benefit from anticoagulation. Unfortunately, most knowledge-translation attempts have failed to improve the quality of anticoagulation on a national basis. Clearly, new strategies are necessary.

\section{Part 2. Future Anticoagulant Therapy for AF: The State of the Art}

To improve upon warfarin, new oral anticoagulants must be at least as effective and safe, and more convenient. Ideally they should not require frequent coagulation monitoring and should have minimal food, drug and lifestyle interactions. New agents meeting these criteria are the direct thrombin inhibitor, dabigatran, and the factor Xa inhibitor, rivaroxaban. The factor Xa inhibitors, apixaban and edoxaban, are in advanced stages of clinical development and also have the potential to meet these criteria.

Results from the 18,113 patient RE-LY trial have established a new standard in efficacy and safety for stroke prevention in AF. ${ }^{20}$ (See Table 1 for summary of main results.) Compared with dose-adjusted warfarin, dabigatran $150 \mathrm{mg}$ bid was superior for

Table 1: Summary of efficacy and safety outcomes in RE-LY ${ }^{17}$

\begin{tabular}{|c|c|c|c|c|c|c|c|c|c|c|}
\hline \multirow[t]{2}{*}{ Event } & \multicolumn{2}{|c|}{$\begin{array}{c}\text { Dabigatran, } \\
110 \mathrm{mg} \\
(\mathrm{N}=6015)\end{array}$} & \multicolumn{2}{|c|}{$\begin{array}{c}\text { Dabigatran, } \\
150 \mathrm{mg} \\
(\mathrm{N}=6076)\end{array}$} & \multicolumn{2}{|c|}{$\begin{array}{l}\text { Warfarin } \\
(\mathrm{N}=6022)\end{array}$} & \multicolumn{2}{|c|}{$\begin{array}{c}\text { Dabigatran, } 110 \text { mg, } \\
\text { vs Warfarin }\end{array}$} & \multicolumn{2}{|c|}{$\begin{array}{c}\text { Dabigatran, } 150 \text { mg, } \\
\text { vs Warfarin }\end{array}$} \\
\hline & $\begin{array}{c}\text { \# of } \\
\text { patients }\end{array}$ & $\% / y r$ & $\begin{array}{c}\text { \# of } \\
\text { patients }\end{array}$ & $\% / y r$ & $\begin{array}{c}\text { \# of } \\
\text { patients }\end{array}$ & $\% / y r$ & $\begin{array}{l}\text { Relative Risk } \\
\qquad(95 \% \mathrm{Cl})\end{array}$ & P Value $\ddagger$ & $\begin{array}{l}\text { Relative Risk } \\
\qquad(95 \% \mathrm{Cl})\end{array}$ & P Value \\
\hline $\begin{array}{l}\text { Stroke or systemic } \\
\text { embolism*† }\end{array}$ & 182 & 1.53 & 134 & 1.11 & 199 & 1.69 & $0.91(0.74-1.11)$ & 0.34 & $0.66(0.53-0.82)$ & $<0.001$ \\
\hline Net clinical benefit & 844 & 7.09 & 832 & 6.91 & 901 & 7.64 & $0.92(0.84-1.02)$ & 0.10 & $0.91(0.82-1.00)$ & 0.04 \\
\hline Myocardial infarction & 86 & 0.72 & 89 & 0.74 & 63 & 0.53 & $1.35(0.98-1.87)$ & 0.07 & $1.38(1.00-1.91)$ & 0.048 \\
\hline $\begin{array}{l}\text { Death from vascular } \\
\text { causes }\end{array}$ & 289 & 2.43 & 274 & 2.28 & 317 & 2.69 & $0.90(0.77-1.06)$ & 0.21 & 0.85 (0.72-0.99) & 0.04 \\
\hline Major bleeding & 322 & 2.71 & 375 & 3.11 & 397 & 3.36 & $0.80(0.69-0.93)$ & 0.003 & $0.93(0.81-1.07)$ & 0.31 \\
\hline $\begin{array}{l}\text { Life threatening } \\
\text { bleeding }\end{array}$ & 145 & 1.22 & 175 & 1.45 & 212 & 1.80 & $0.68(0.55-0.83)$ & $<0.001$ & $0.81(0.66-0.99)$ & 0.04 \\
\hline $\begin{array}{l}\text { Gastrointestinal } \\
\text { bleeding }\end{array}$ & 133 & 1.12 & 182 & 1.51 & 120 & 1.02 & $1.10(0.86-1.41)$ & 0.43 & 1.50 (1.19-1.89) & $<0.001$ \\
\hline $\begin{array}{l}\text { Intracranial } \\
\text { hemorrhage** }\end{array}$ & 27 & 0.23 & 36 & 0.30 & 87 & 0.74 & $0.31(0.20-0.47)$ & $<0.001$ & $0.40(0.27-0.60)$ & $<0.001$ \\
\hline
\end{tabular}

All analyses were based on the time to first event. * Data are shown for all patients who had at least one event. $\dagger$ P-value for non-inferiority $<0.001$ for both doses of dabigatran compared with warfarin. $\ddagger \mathrm{P}$ values are for superiority. I Net clinical benefit was a composite of stroke, systemic embolism, pulmonary embolism, myocardial infarction, death, or major bleeding. ** Intracranial hemorrhage: defined as hemorrhagic stroke, subdural hemorrhage or subarachnoid hemorrhage. 
Table 2: Summary of preliminary results from ROCKET-AF ${ }^{22 *}$

\begin{tabular}{l|c|c|cc}
\hline Event & $\begin{array}{c}\text { Rivaroxaban } \\
(\mathbf{N}=7081)\end{array}$ & $\begin{array}{c}\text { Warfarin } \\
\mathbf{( N = 7 0 9 0 )}\end{array}$ & \multicolumn{2}{|c}{ Rivaroxaban vs Warfarin } \\
& $\% / y r$ & $\% / y r$ & Hazard Ratio & P Value \\
Stroke and non-CNS embolism & 2.12 & 2.42 & $0.88(0.74-1.03)$ & 0.117 \\
Major bleeding & 3.60 & 3.45 & $1.04(0.90-1.20)$ & 0.576 \\
Intracranial hemorrhage & 0.49 & 0.74 & $0.67(0.47-0.94)$ & 0.019 \\
Critical organ bleeding & 0.82 & 1.18 & $0.69(0.53-0.91)$ & 0.007 \\
Bleeding causing death & 0.24 & 0.48 & $0.50(0.31-0.79)$ & 0.003 \\
\hline
\end{tabular}

* based on the intention-to-treat population.

prevention of stroke or systemic embolism with similar rates of major bleeding. The $110 \mathrm{mg}$ bid dose of dabigatran was noninferior to warfarin for prevention of stroke or systemic embolism and was associated with lower rates of major bleeding. The comparisons between dabigatran and warfarin were openlabel in a PROBE design. Both doses of dabigatran had a lower risk of life-threatening bleeding and intracranial hemorrhage compared to warfarin. Patients treated with warfarin in this trial had a mean TTR of $64 \%$, representing warfarin "at its best". The $0.58 \%$ absolute reduction in annual risk of stroke (ischemic or hemorrhagic) or systemic embolism demonstrated with the 150 mg dose translates to five to six fewer events per 1000 patients treated, with no increase in major bleeding.

There was a significant interaction between drug treatment and age for bleeding outcomes; dabigatran $110 \mathrm{mg}$ bid was associated with a lower risk of major extracranial bleeding compared to warfarin in patients aged $<75$ years; in patients $\geq$ age 75 years, dabigatran $110 \mathrm{mg}$ bid compared with warfarin was associated with a similar rate of extracranial major bleeding whereas dabigatran $150 \mathrm{mg}$ bid compared with warfarin was associated with an increased rate of extracranial major bleeding. ${ }^{20(a)}$ Both doses of dabigatran compared with warfarin were associated with a reduction in intracranial hemorrhage irrespective of age. Dyspepsia was more common with dabigatran than warfarin. Gastrointestinal bleeding occurred more frequently with the $150 \mathrm{mg}$ dose of dabigatran vs. warfarin and both doses of dabigatran were associated with a numerical excess of myocardial infarctions. ${ }^{21}$ RE-LY excluded patients with severe renal impairment (creatinine clearance $<30$ $\mathrm{ml} /$ minute). Patients with a recent ischemic stroke ( $<2$ weeks) or previous intracranial hemorrhage were also excluded, so results in these subgroups are unknown.

Preliminary results from ROCKET-AF, a double-blind phase III trial comparing once-daily rivaroxaban to dose-adjusted warfarin in a higher risk patient population than RE-LY, were presented in 2010 (not yet published at the time of this writing). ${ }^{22}$ These results, summarized in Table 2, demonstrated that rivaroxaban was non-inferior to warfarin for the prevention of

Table 3: Summary of efficacy and safety outcomes in AVERROES ${ }^{23}$

\begin{tabular}{|c|c|c|c|c|c|c|}
\hline \multirow[t]{2}{*}{ Event } & \multicolumn{2}{|c|}{$\begin{array}{l}\text { Apixaban } \\
(\mathrm{N}=\mathbf{2 8 0 8})\end{array}$} & \multicolumn{2}{|c|}{$\begin{array}{c}\text { Aspirin } \\
(\mathrm{N}=2791)\end{array}$} & \multicolumn{2}{|c|}{ Apixaban vs Aspirin } \\
\hline & $\begin{array}{c}\text { \# of } \\
\text { patients }\end{array}$ & $\begin{array}{c}\% / y \\
r\end{array}$ & $\begin{array}{c}\text { \# of } \\
\text { patients }\end{array}$ & $\% / y r$ & $\begin{array}{l}\text { Hazard Ratio } \\
(95 \% \mathrm{Cl})\end{array}$ & P Value \\
\hline Stroke or systemic embolism* & 51 & 1.6 & 113 & 3.7 & $0.45(0.32-0.62)$ & $<0.001$ \\
\hline Net benefit $†$ & 163 & 5.3 & 220 & 7.2 & $0.74(0.60-0.90)$ & 0.003 \\
\hline Ischemic stroke & 35 & 1.1 & 93 & 3.0 & $0.37(0.25-0.55)$ & $<0.001$ \\
\hline Major bleeding & 44 & 1.4 & 39 & 1.2 & $1.13(0.74-1.75)$ & 0.57 \\
\hline Intracranial bleeding & 11 & 0.4 & 13 & 0.4 & $0.85(0.38-1.90)$ & 0.69 \\
\hline
\end{tabular}

All analyses were based on the time to first event. * Data are shown for all patients who had at least one event. $\dagger$ Net benefit was a composite of stroke, systemic embolism, myocardial infarction, death from vascular cause, or major bleeding. 
Table 4: Estimated number of additional Canadian strokes prevented if dabigatran $150 \mathrm{mg}$ bid were used instead of warfarin*

\begin{tabular}{|c|c|c|c|c|c|c|c|c|}
\hline \multirow[t]{2}{*}{ CHADS $_{2}$ Score } & \multicolumn{2}{|c|}{$\begin{array}{l}\text { Estimated \# Canadian } \\
\text { patients with AF (assuming } \\
\qquad N=250,000 \text { ) }\end{array}$} & \multicolumn{2}{|c|}{$\begin{array}{c}\text { Annual absolute risk } \\
\text { reduction with } 150 \mathrm{mg} \\
\text { dabigatran vs. warfarin }\end{array}$} & \multicolumn{2}{|c|}{$\begin{array}{l}\text { Estimated \# of additional } \\
\text { events prevented annually if } \\
\text { dabigatran } 150 \mathrm{mg} \text { bid } \\
\text { replaced warfarin in one half } \\
\text { of AF patients }\end{array}$} & \multicolumn{2}{|c|}{$\begin{array}{c}\text { Estimated \# of additional } \\
\text { events prevented annually if } \\
\text { dabigatran } 150 \mathrm{mg} \text { bid replaced } \\
\text { warfarin in one third of AF } \\
\text { patients }\end{array}$} \\
\hline & $\#$ & $(\%)^{7}$ & $\begin{array}{l}\text { Stroke or } \\
\text { systemic } \\
\text { embolism }\end{array}$ & $\begin{array}{l}\text { Intracranial } \\
\text { hemorrhage }\end{array}$ & $\begin{array}{l}\text { Stroke or } \\
\text { systemic } \\
\text { embolism }\end{array}$ & $\begin{array}{l}\text { Intracranial } \\
\text { hemorrhage }\end{array}$ & $\begin{array}{l}\text { Stroke or } \\
\text { systemic } \\
\text { embolism }\end{array}$ & $\begin{array}{l}\text { Intracranial } \\
\text { hemorrhage }\end{array}$ \\
\hline $\begin{array}{c}0 \\
\text { (low risk) }\end{array}$ & 50,000 & (20.0\%) & - & - & - & - & & \\
\hline $\begin{array}{c}1 \\
\text { (low-moderate risk) }\end{array}$ & 84,500 & $(33.8 \%)$ & $0.40 \%$ & $0.31 \%$ & 169 & 131 & 113 & 87 \\
\hline $\begin{array}{c}2 \\
\text { (moderate-high risk) }\end{array}$ & 69,250 & $(27.7 \%)$ & $0.54 \%$ & $0.40 \%$ & 187 & 139 & 125 & 92 \\
\hline $\begin{array}{c}\geq 3 \\
\text { (highest risk) }\end{array}$ & 46,000 & (18.4\%) & $0.80 \%$ & $0.58 \%$ & 184 & 134 & 123 & 89 \\
\hline
\end{tabular}

* The estimated number of events prevented annually was calculated by using the ARR for dabigatran $150 \mathrm{mg}$ bid vs. warfarin from the RE-LY trial results stratified by CHADS2 score ${ }^{20}$ and applying it to the Canadian AF population. The numbers are likely to be an underestimate, because it is based on an assumption that all patients would otherwise be taking warfarin and well controlled (TTR 64\%, as per RELY) in practice. We also assumed that only one third or one half of all AF patients would be eligible for anticoagulant therapy with dabigatran $150 \mathrm{mg}$ bid (e.g., age $<80$ years, no contraindications) and adhere to therapy for one year without discontinuation.

stroke and non-central nervous system (CNS) embolism with similar rates of major bleeding (and lower rates of intracranial hemorrhage, critical organ hemorrhage and fatal hemorrhage). The median TTR in patients treated with warfarin was $58 \%$. Rates of dyspepsia and myocardial infarction were not increased with rivaroxaban compared to warfarin.

Results from AVERROES, a phase III trial comparing apixaban with ASA, were recently published. ${ }^{23}$ Apixaban was shown to be superior to ASA in preventing stroke or systemic embolism (RRR $>50 \%$ ) in AF patients who were considered unsuitable for warfarin therapy, and the two groups had similar rates of major bleeding. (See Table 3 for a summary of main results.)

Phase III results comparing apixaban and edoxaban to doseadjusted warfarin are anticipated in 2011 and 2012, respectively.

\section{Implementation in the Canadian Setting}

New guidelines state that individuals with non-valvular AF and CHADS2 score $\geq 1$ would benefit from treatment with an anticoagulant. $^{24-26}$ Using data from RE-LY applied to the Canadian AF population, one can estimate that hundreds of strokes (ischemic and hemorrhagic) could potentially be prevented each year in Canada by treating patients with dabigatran $150 \mathrm{mg}$ bid instead of warfarin (Table 4). The greatest impact of the new oral anticoagulants at a population level, however, will be their potential to reach the large population of currently untreated patients who could benefit from warfarin but do not receive it. (Figure) Targeting this group of untreated patients represents a major opportunity to reduce stroke rates. For example, if even a fraction of the total population of anticoagulant-eligible patients in Canada were switched from
ASA to apixaban, we estimate that hundreds of additional strokes would be prevented annually.

We propose a prioritization hierarchy based on stroke risk for determining how dabigatran can be best utilized to improve patient outcomes. The same approach can be adapted to other new agents that demonstrate favorable efficacy/safety profiles compared to warfarin and aspirin in phase III trials. Patients at moderate to high stroke risk (CHADS2 score $\geq 2$ ) would be a logical "highest priority" group. This population includes patients with a prior stroke or transient ischemic attack, as well as those with $\geq 2$ stroke risk factors: age $\geq 75$ years, hypertension, diabetes mellitus, and/or left ventricular dysfunction. Patients at lower stroke risk $\left(\mathrm{CHADS}_{2}\right.$ score $\left.=1\right)$ may be a "second priority" group. In determining the hierarchical cut-point for the use of dabigatran, a broad view of the healthcare system must be taken that encompasses population effectiveness, safety, and costs to the system as a whole. Patients not well controlled on warfarin should be considered a high priority.

Despite the advantages of new treatments, warfarin remains a time-tested therapy for AF (and many other indications), and system-level strategies to improve warfarin's effectiveness still need to be supported and enhanced.

It is anticipated that the new anticoagulants will enable many more patients to be effectively anticoagulated than has been possible with warfarin because they are easier to initiate, do not require coagulation monitoring, are more convenient for patients and physicians, and there may be less apprehension about bleeding risks. For dabigatran, while the $150 \mathrm{mg}$ bid dose provides the greatest efficacy for stroke risk reduction, the Canadian product monograph recommends the $110 \mathrm{mg}$ bid dose for individuals aged $\geq 80$ years (although $\geq 75$ years may be 
most appropriate based on new analyses). ${ }^{20(a)}$ The $110 \mathrm{mg}$ bid dose is recommended if creatinine clearance is $30-50 \mathrm{ml} /$ minute, and it may become a preferred treatment option for patients judged to be at higher than average bleeding risk for whom clinicians may have otherwise excluded from warfarin therapy altogether. For example, high CHADS2 score patients who have had a previous intracranial hemorrhage are frequently excluded from warfarin therapy, but some may be reasonable candidates to consider for low-dose dabigatran, e.g. selected stable patients with a remote (non-acute) deep hypertensive intracerebral hemorrhage or magnetic resonance image (MRI)-detected microhemorrhages (although such patients were not studied in RE-LY). The rapid onset of action of the new anticoagulants is anticipated to streamline hospital and ED discharge protocols and facilitate rapid outpatient secondary prevention management for AF patients with acute transient ischemic attack. The safety of early initiation of the new anticoagulants in the acute/subacute phase after a transient ischemic attack or ischemic stroke, however, is unknown and is in need of study; caution is therefore advised. Also, given the widespread tendency toward overdiagnosis of transient ischemic attacks, accurate patient diagnosis and risk stratification are essential to avoid inappropriate anticoagulation of low risk patients.

\section{Part 3. Limitations and Caveats with the New Oral Anticoagulants}

While the development of new oral anticoagulants for AF represents a welcome advance for the stroke prevention field, there are recognized limitations. One concern is the lack of a specific antidote (e.g. vitamin $\mathrm{K}$, prothrombin complex concentrate) for the emergency reversal of anticoagulant effect of the new agents in the event of major bleeding or need for an emergency procedure or surgery; hospital protocols for managing such situations need to be urgently developed. There is currently no widely available way to measure the intensity of anticoagulation of the new drugs like there is with warfarin. The new drugs might make many patients ineligible for intravenous thrombolytic therapy, e.g. tPA in the event of an acute ischemic stroke (the role of endovascular rescue attempts with mechanical clot removal will inevitably need to be explored).

The lack of a need for routine coagulation monitoring that is a distinct advantage of the new drugs also represents a potential danger in real-world practice outside of a trial setting if patients stop being monitored and adherence stops being assessed. Given the short half-life of the new agents compared to warfarin, the consequence of missed doses could be more significant in terms of stroke risks. Therefore, concerted efforts to promote patient education and reinforce adherence to therapy will become more important than ever. Extra caution is advised in patients with renal impairment and periodic monitoring for declining renal function that may preclude continued therapy with a new anticoagulant should be considered. Phase IV surveillance studies will be important to ensure appropriate use and safety of the new agents in practice and to ensure the new agents do not become over-prescribed, i.e. for inappropriate indications. As with any new drug, we must tread cautiously, and clinicians and patients cannot risk becoming cavalier about anticoagulant therapy. The Canadian Cardiovascular Pharmacists Network has developed a pocket card of useful anticoagulant prescribing information to assist clinicians. ${ }^{28}$ To avoid loss of potency, dabigatran capsules should not be removed from the original bottle or packaging in which it was dispensed and should be used within 60 days.$^{27}$ For all anticoagulated patients, regardless of the agent, ensuring optimal blood pressure control and avoiding concomitant antiplatelet therapy (unless otherwise indicated) will help to minimize bleeding risks.

\section{SUMMARY}

Preventing more AF-related strokes in Canada must become a top priority for clinicians, hospitals and government. Although warfarin is highly efficacious, we are facing an epidemic of strokes because too many eligible patients are not receiving warfarin and because stable therapeutic INR control can be difficult to achieve. The recent regulatory approval of dabigatran marks a milestone in the history of AF management since the introduction of warfarin about 60 years ago. Taken together with recent trial results for rivaroxaban and apixaban and the ongoing development of other oral anticoagulant drugs, there is real promise that many more patients with AF will be effectively anticoagulated and better protected against stroke. After decades of inertia with warfarin, we are now finally on the verge of a new treatment era. Careful patient selection and careful follow-up of patients prescribed new anticoagulants will be crucial in determining how successfully trial results will be translated into real world practice.

\section{ACKNOWLEDGEMENTS}

David Gladstone holds a Clinician Scientist Award from the Heart and Stroke Foundation of Ontario, and is supported by the Heart and Stroke Foundation Centre for Stroke Recovery.

Boehringer Ingelheim (BI) Canada Ltd. provided an unrestricted grant to sponsor a one day meeting attended by the authors that led to the development of this manuscript. Boehringer Ingelheim Canada Ltd. was neither represented at meetings and teleconferences, nor provided any input into the writing or editing of the manuscript.

\section{DECLARATIONS}

Dr. Gladstone is PI of the EMBRACE trial of atrial fibrillation detection that received a peer-reviewed operating grant from the Canadian Stroke Network. He is PI of an atrial fibrillation registry study that received a peer-reviewed operating grant from the Ontario Stroke Network. He has received speaker fees for CME events and/or advisory boards from Sanofi Aventis, Bristol Myers Squibb, and Boehringer-Ingleheim, and advisory board/ consulting honouraria from Bayer. He was an ad hoc outcome event adjudicator for the RE-LY trial.

Dr. Eikelboom has received consulting fees and/or honoraria from Astra Zeneca, Boehringer Ingelheim, Bristol Myers Squibb, Corgenix, Daiichi Sankyo, Eisai, Eli Lilly, Glaxo Smith Kline, Haemoscope, McNeil, Sanofi Aventis. Grants and/or in-kind support from Accumetrics, Aspirin Works, Bayer, Boehringer Ingelheim, Bristol Myers Squibb, Corgenix, Dade Behring, Glaxo Smith Kline and Sanofi Aventis. Dr. Eikelboom has served on Study Committees for the RE-LY, AVERROES and ROCKET-AF trials.

Dr. Cox sits on advisory boards for Astra Zeneca, Bayer, Boehringer Ingelheim, BMS/Sanofi Aventis Pharmaceuticals Partnership and Sanofi Aventis. He has participated in research 
funded by the Canadian Institutes of Health Research, Heart and Stroke Foundation, Nova Scotia Health Research Foundation, Merck, Pfizer and Sanofi Aventis.

Karen Earl has received fees for providing accredited continuing medical education programs sponsored by Boehringer Ingelheim, Bayer, Astra Zeneca, Sanofi Aventis, Bristol Myers Squibb, Pfizer, Lilly, Roche and Edwards Lifesciences. She has also received consulting fees from Boehringer Ingelheim, Astra Zeneca, Baxter and Astellas.

Dr. Bungard is on the Advisory Board for Astra Zeneca, Bayer, Pfizer, Roche Diagnostics. Travel, speaker honoraria sponsored by Boehringer Ingelheim and research funding \& presentation honoraria from Dupont Pharma.

Dr. Bell has received consultation fees, research and or travel grants from the following commercial institutions that may have an interest in the submitted material: Sanofi Aventis Canada, Boehringer Ingelheim Canada, Bristol Myers Squibb Canada, Bayer Canada, Daiichi Sankyo Inc.

Dr. Huynh has received grant and advisory board honouraria from Boehringer Ingelheim.

Dr. Dean has received speaker's honoraria from Boehringer Ingelheim.

Dr. Dorian has received consulting fees and research support from Boehringer Ingelheim, Bristol Myers Squibb/Pfizer and Bayer, and is a steering committee member for the ARISTOTLE trial.

Dr. Shuaib has been on advisory boards and received honouraria from Boehringer Ingelheim, Bayer, Bristol Myers Squibb, Pfizer, and Sanofi Aventis.

\section{REFERENCES}

1. Public Health Agency of Canada. 2009 Tracking Heart Disease and Stroke in Canada [Internet]. [cited 2011 Mar 21]. Available from: http://www.phac-aspc.gc.ca/publicat/2009/cvd-avc/indexeng.php.

2. Gladstone DJ, Blakely J, Dorian P, et al. Detecting paroxysmal atrial fibrillation after ischemic stroke and transient ischemic attack: if you don't look, you won't find. Stroke. 2008;39:e78-9.

3. Statistics Canada. Table 4 Population estimates by sex and age group as of July 1, 2010, Canada [Internet]. [cited 2011 Mar 21]. Available from: http://www.statcan.gc.ca/daily-quotidien/1009 29/dq100929b-eng.htm.

4. Statistics Canada. Projected population by age group according to three projection secenarios at July 1, 2036 [Internet]. [cited 2011 Mar 21]. Available from: http://www40.statcan.gc.ca/101/cst01/ demo08d-eng.htm.

5. Santini M, Ricci RP. The worldwide social burden of atrial fibrillation: what should be done and where do we go? J Interv Card Electrophysiol. 2006 Dec;17(3):183-8.

6. Hart RG, Pearce LA, Agullar MI. Meta-analysis: antithrombotic therapy to prevent stroke in patients who have nonvalvular atrial fibrillation. Ann Intern Med. 2007;146:857-67.

7. Zimetbaum PJ, Thosani A, Yu HT, et al. Are atrial fibrillation patients receiving warfarin in accordance with stroke risk? Am J Med. 2010;123:446-53.

8. van Walraven C, Jennings A, Oake N, Fergusson D, Forster AJ. Effect of study setting on anticoagulation control. A systematic review and metaregression. Chest. 2006;129:1155-66.

9. Matchar DB, Samsa GP, Cohen SJ, Oddone EZ, Jurgelski AE. Improving the quality of anticoagulation of patients with atrial fibrillation in managed care organizations: results of the managing anticoagulation services trial. Am J Med. 2002;113(1): 42-51.

10. Gladstone DJ, Bui E, Fang J, et al. Potentially preventable strokes in high-risk patients with atrial fibrillation who are not adequately anticoagulated. Stroke. 2009;40:235-40.
11. O'Donnell M, Oczkowski W, Fang J, et al. Preadmission antithrombotic treatment and stroke severity in patients with atrial fibrillation and acute ischaemic stroke: an observational study. Lancet Neurol. 2006;5(9):749-54.

12. Connolly SJ, Pogue J, Eikelboom J, et al. Benefit of oral anticoagulant over antiplatelet therapy in atrial fibrillation depends on the quality of international normalized ratio control achieved by centers and countries as measured by time in therapeutic range. Circulation. 2008;118:2029-37.

13. Bungard TJ, Gardner L, Archer S, et al. Evaluation of a pharmacistmanaged anticoagulation clinic - improving patient care. Open Medicine. 2009;3(1):16-21.

14. Bungard TJ, Ackman ML, Ho G, Tsuyuki RT. Adequacy of anticoagulation in patients with atrial fibrillation coming to a hospital. Pharmacotherapy. 2000;20(9):1060-5.

15. Mariano Z, Triveri M, Atzema $C$, Dorian P. Utilization of anticoagulant therapy in the emergency department for patients with atrial fibrillation at high risk of stroke [abstract]. Can J Cardiol. 2009;25 Suppl B:S301.

16. Glader EL, Sjolander M, Eriksson M, Lundberg M. Persistent use of secondary prevention drugs declines rapidly during the first 2 years after stroke. Stroke. 2010;41:397-401.

17. Gallagher AM, Rietbrock S, Plumb J, Van Staa TP. Initiation and persistence of warfarin or aspirin in patients with chronic atrial fibrillation in clinical practice: do the appropriate patients receive stroke prophylaxis? J Thromb Haemost. 2008;6:1500-6.

18. Budnitz DS, Pollock DA, Weidenbach KN, Mendelsohn AB, Schroeder TJ, Annest JL. National surveillance of emergency department visits for outpatient adverse drug events. JAMA. 2006;296(15):1858-66.

19. Bungard TJ, Ghali WA, McAlister, et al. Physicians' perceptions of the benefits and risks of warfarin for patients with nonvalvular atrial fibrillation. CMAJ. 2001;165(3):301-2.

20. Connolly SJ, Ezekowitz MD, Yusuf S, et al. Dabigatran versus warfarin in patients with atrial fibrillation. N Engl J Med. 2009; 361:1139-51.

20a. Eikelboom JW, Wallentin L, Connolly SJ, et al. Risk of bleeding with 2 doses of Dabigatran compared with Warfarin in older and younger patients with atrial fibrillation: An analysis of the randomized evaluation of long-term anticoagulant therapy (RELY) trial. Circulation 2011;123(21):2363-72.

21. Connolly SJ, Ezekowitz MD, Yusuf S, et al. Newly identified events in the RE-LY trial. N Engl J Med. 2010;363(19):1875-6.

22. Mahaffey KW, Fox KAA, ROCKET AF Investigators. Rivaroxaban once-daily oral direct factor Xa inhibition compared with vitamin $\mathrm{K}$ antagonism for prevention of stroke and embolism trial in atrial fibrillation. Presented AHA Nov. 15, 2010. Available from: https://www.dtmi.duke.edu/website-administra tion/files/ROCKET-AF-LBCT-FINAL.ppt/view.

23. Connolly SJ, Eikelboom J, Joyner C, et al. Apixaban in patients with atrial fibrillation. N Engl J Med. 2011;364(9):806-17.

24. Camm AJ, Kirchhof P, Lip GYH, et al. Guidelines for the management of atrial fibrillation: the Task Force for the Management of Atrial Fibrillation of the European Society of Cardiology (ESC). Eur Heart J. 2010;31(19):2369-429.

25. Cairns JA, Connolly SJ, McMurtry S, Stephenson M, Talajic M, CCS Atrial Fibrillation Guidelines Committee. Canadian Cardiovascular Society atrial fibrillation guidelines 2010: prevention of stroke and systemic thromboembolism in atrial fibrillation and flutter. Can J Cardiol. 2011;27(1):74-90.

26. Lindsay MP, Gubitz G, Bayley M, Hill MD, Davies-Schinkel C, Singh S, Phillips S. Canadian best practice recommendations for stroke care (update 2010). On behalf of the Canadian Stroke Strategy Best Practices and Standards Writing Group. 2010; Ottawa, Ontario Canada: Canadian Stroke Network. [cited 2011 Mar 21]. Available from: www.strokebestpractices.ca.

27. U.S. Food and Drug Administration. FDA Drug Safety Communication: Special storage and handling requirements must be followed for Pradaxa (dabigatran etexilate mesylate) capsules [Internet]. [cited 2011 Apr 6]. Available from: http://www.fda.gov/Drugs/DrugSafety/ucm248746.htm.

28. Bungard TJ, Bucci C, Kertland H, Pickering J, Semchuk WM. Preventing stroke in atrial fibrillation patients: a systematic approach. Can Pharm J. [In Press 2011]. 